\title{
Preventive Practices of Tuberculosis Patients in a Municipality of Chitwan District, Nepal
}

\author{
Prerna Bansal, ${ }^{1}$ Dipendra Khatiwada, ${ }^{1}$ Hari Prasad Upadhyay ${ }^{1}$ \\ ${ }^{1}$ Department of Community Medicine, College of Medical Sciences, Bharatpur, Chitwan, Nepal.
}

\begin{abstract}
Background: Tuberculosis (TB) is one of the top 10 causes of death worldwide and sixth leading cause of death in Nepal. Preventing new infections of Mycobacterium tuberculosis is crucial to reduce TB burden and death. The source of infection is an open (sputum positive) case of pulmonary tuberculosis. Poor management of TB-related waste like disposal of sputum by patients has been reported as a risk factor for increasing susceptibility to active TB infection. The present study was undertaken to assess preventive measures practiced by TB patients. Methods: A cross-sectional study was conducted among 82 tuberculosis patients who visited the five different DOTs centres of Bharatpur Municipality of Chitwan district, Nepal during December 2016 to February 2017. To find the association between variables chi-square test was used. P-value less than 0.05 were considered as statistically significant. Results: The Mean \pm SD of age of patients was $37.02 \pm 18.90$ years. $67.10 \%$ of the patients received health education on preventive measures. $59.8 \%$ of the respondents had good practice on prevention measures of TB. Only 3.70\% used burning method for the sputum disposal after diagnosis of TB. None of the respondents used boiling method for the disposal of sputum. Among all only $6 \%$ practiced safe method of sputum disposal. The statistically significant variables with health education were preventive measures like self isolation $\left(\chi^{2}=7.54, \mathrm{p}=0.006\right)$, covering face while coughing and sneezing $\left(\chi^{2}=4.113, p=0.043\right)$ and keeping surrounding clean $\left(\chi_{2} 2=7.880, p=0.005\right)$. Conclusions: Patients and family members should be well educated on practicing different preventive measures by further strengthening the preventive measure strategy in the transmission of tuberculosis if we envisioned to end TB by 2035 .
\end{abstract}

Keywords: health education; preventive measures; preventive practices; sputum disposal; tuberculosis.

\section{INTRODUCTION}

Tuberculosis (TB) is one of the top 10 causes of death worldwide and sixth leading cause of death in Nepal among which more than $95 \%$ of TB deaths occur in low- and middle-income countries. ${ }^{1,2}$ Preventing new infections of Mycobacterium tuberculosis as well as their progression to active TB disease is crucial to reduce TB burden and death which is envisioned in the National Tuberculosis Programme of Nepal. ${ }^{3}$ The source of infection is an open (sputum positive) case of pulmonary tuberculosis and it has been estimated that a cough can generate 3000 droplet nuclei which can be released during normal activities like talking or spontaneously during breathing. ${ }^{4}$ People with active TB can infect $10-15$ other people through close contact over the course of a year. ${ }^{1}$ Poor management of TB-related waste has been reported as a risk factor for increasing susceptibility to active TB infection. ${ }^{5-8}$ The transmission of Pulmonary Tuberculosis (PTB) is attributed to indiscriminate disposal of sputum by patients. ${ }^{9}$ Also, it is important that the TB patient have the crucial knowledge regarding the mode of spread of disease, hazards faulty way of coughing and indiscriminate sputum disposal at home as well as in community. ${ }^{10}$ Recommendations have been made concerning safe sputum disposal techniques for health care and domiciliary contexts. ${ }^{11,12}$

To prevent the transmission of the disease it is important to know the preventive practices not only at healthcare but at patient level too. Therefore, the present study was undertaken to assess preventive measures practiced by TB patients.

\section{METHODS}

A cross-sectional study was conducted on tuberculosis patients visiting the five different DOTS centres of Bharatpur Municipality of Chitwan district, Nepal during December 2016 to February 2017. Sample size was determined by using the formula. The prevalence of all types of tuberculosis

Correspondence: Dr. Prerna Bansal, Department of Community Medicine, College of Medical Sciences, Bharatpur10, Chitwan, Nepal. Email: drprernabg@gmail.com. Phone: +977-9841529167. ORCID: https://orcid.org/0000-00017876-6637. DOI: 10.3126/jcmsn.v15i1.23165. Article received: 2018-11-20. Article accepted: 2019-02-20. 
Bansal et al. Preventive Practices of Tuberculosis Patients in a Municipality of Chitwan..

cases in Nepal is $2.41 \% .13$ So, considering $p=0.0241$ and $\mathrm{q}=0.9759$. The $\mathrm{z}$-score value at $95 \%$ Confidence interval is 1.96 . The desirable error was $4 \%$, the required minimum sample size of this study was 57 , and including $10 \%$ non-response error the sample size was 82. Non-probability (convenient) sampling technique was used to collect the data. The total of 82 patients who visited these DOTS clinic during the study duration were enrolled in the study. Ethical approval was taken from Institutional Review Committee of College of Medical Sciences and written permission was sought from District Public Health Office, Chitwan, Nepal. Written informed consent was taken from all the respondents and in case of minors $(<16$ years old) it was taken from the parent/legal guardian. Questionnaire method was used to collect the data from the patients. Safe disposal of sputum was considered on those patient who received sputum in gauze or paper handkerchiefs and best destroyed by burning, or if considerable amount best destroyed by methods like boiling, autoclaving or by using 5\% cresol.14 The collected data was first checked for completeness and consistency. Different variables were coded and entered in Epi Data 3.1 and analysed by using SPSS version 16 software. The entered data were cleaned and edited before subsequent analysis. To find the significant association between categorical variables, chi-square test was used. P-value less than 0.05 were considered as statistically significant.

\section{RESULTS}

Out of the 82 patients, $38(53.70 \%)$ were male and remaining $44(41.50 \%)$ were female, male is to female ratio was $0.8: 1$. The range of age of respondents was from 4 years to 77 years. The Mean \pm SD of age of study patients was $37.02 \pm 18.90$ years. About $37(45.1 \%)$ were in the age group of 20 to 40 years, followed by $15(18.3 \%)$ in 40 to 60 years, and $14(17.1 \%)$ were 60 to 80 years age group. 48 $(58.50 \%)$ were from nuclear families and 34 $(41.50 \%)$ were from joint families. Regarding educational status, $29(35.40 \%)$ were illiterate and 53 $(64.60 \%)$ were literate. Regarding occupation maximum patients i.e. $28(34.10 \%)$ were house workers, $17(20.70 \%)$ were students, $14(17.10 \%)$ were involved in service and $13(15.9 \%)$ were into farming. Maximum $65(79.30 \%)$ were Hindus by religion followed by Buddhists $14(17.10 \%)$ and 2 $(2.40 \%)$ were Christians. Most of the patients were single $56(68.30 \%)$ and $22(26.80 \%)$ were married. According to the income level, $36(43.90 \%)$ earned monthly between ten thousand to twenty thousand NRs only few $2(2.40 \%)$ earned 30 to 40 thousand NRs (Table 1).
Table 1. Socio-demographic characteristics of the study patients. $(n=82)$

\begin{tabular}{|c|c|c|}
\hline Characteristics & Frequency & Percentage \\
\hline \multicolumn{3}{|l|}{ Age (Years) } \\
\hline$<20$ & 16 & $19.5 \%$ \\
\hline $20-40$ & 37 & $45.2 \%$ \\
\hline $40-60$ & 15 & $18.3 \%$ \\
\hline $60-80$ & 14 & $17.1 \%$ \\
\hline Mean $\pm \mathrm{SD}$ & $(37.02 \pm 18.90)$ years & \\
\hline \multicolumn{3}{|l|}{ Gender } \\
\hline Male & 38 & $46.3 \%$ \\
\hline Female & 44 & $53.70 \%$ \\
\hline \multicolumn{3}{|l|}{ Type of family } \\
\hline Nuclear & 48 & $58.50 \%$ \\
\hline Joint & 34 & $41.50 \%$ \\
\hline \multicolumn{3}{|c|}{ Educational status } \\
\hline Illiterate & 29 & $35.40 \%$ \\
\hline Literate & 53 & $64.60 \%$ \\
\hline \multicolumn{3}{|l|}{ Occupation } \\
\hline Farming & 13 & $15.90 \%$ \\
\hline Service & 14 & $17.10 \%$ \\
\hline Business & 9 & $11 \%$ \\
\hline House worker & 28 & $34.10 \%$ \\
\hline Social service & 1 & $1.20 \%$ \\
\hline Students & 17 & $20.70 \%$ \\
\hline \multicolumn{3}{|l|}{ Religion } \\
\hline Buddhist & 14 & $17.10 \%$ \\
\hline Christian & 2 & $2.40 \%$ \\
\hline Hindu & 65 & $79.30 \%$ \\
\hline Not know & 1 & $1.20 \%$ \\
\hline \multicolumn{3}{|l|}{ Marital status } \\
\hline Single & 56 & $68.30 \%$ \\
\hline Married & 22 & $26.80 \%$ \\
\hline Divorce & 1 & $1.20 \%$ \\
\hline Widow & 3 & $3.70 \%$ \\
\hline \multicolumn{3}{|l|}{ Income } \\
\hline$<10000$ & 21 & $25.60 \%$ \\
\hline 10000 to 20000 & 36 & $43.90 \%$ \\
\hline 20000 to 30000 & 16 & $19.50 \%$ \\
\hline 30000 to 40000 & 2 & $2.40 \%$ \\
\hline$>40000$ & 7 & $8.50 \%$ \\
\hline
\end{tabular}


Bansal et al. Preventive Practices of Tuberculosis Patients in a Municipality of Chitwan..

$68(83 \%)$ were in category I of DOTs treatment whereas $14(17 \%)$ were in category II. History of TB in family was not present in $64(78 \%)$ while 18 $(22 \%)$ patients had the history of TB in the family. Likewise, $55(67.10 \%)$ had received health education on preventive measures while 27 $(32.90 \%)$ had not received health education on preventive measures of TB (Table 2).

\begin{tabular}{|c|c|c|}
\hline Characteristics & Frequency & Percentage \\
\hline DOTS category I & 68 & $83 \%$ \\
\hline Category II & 14 & $17 \%$ \\
\hline \multicolumn{3}{|c|}{ History of TB in family } \\
\hline Yes & 18 & $22 \%$ \\
\hline No & 64 & $78 \%$ \\
\hline \multicolumn{3}{|c|}{$\begin{array}{l}\text { Have you received health } \\
\text { education on preventive } \\
\text { measure }\end{array}$} \\
\hline Yes & 55 & $67.10 \%$ \\
\hline No & 27 & $32.90 \%$ \\
\hline
\end{tabular}

Practice of all preventive measures were found more in literate than illiterate, and more in patients who received health education than who did not. Regarding use of separate utensil majority patients $56.1 \%$ of study patients used separate utensils. Self isolation was practiced by $45.1 \%$ of patients and was significantly associated with receiving health education $(p=0.006)$. Majority of patients used mask $(73.2 \%)$ and covered their face while coughing and sneezing (78\%) which was significantly associated with receiving health education $(\mathrm{p}=0.043)$. Likewise, $45.1 \%$ of patients used any method of sputum disposal. About $62.2 \%$ patients kept their surrounding clean which was significantly associated with educational status $(\mathrm{p}=$ $0.001)$ and receiving health education $(p=0.005)$. Screening of contact and family members was done by only $9.8 \%$ patients. About $3.7 \%$ of people did not practice any of the preventive measures at all. Males practiced all types of preventive measures more than females, except keeping surrounding clean was practiced equally by females $(63.6 \%)$ than males (60.5\%) (Table 3).

The levels of practice of preventive behaviour towards TB were assessed using 7 questions. The types of questions were "Yes", "No". Correct answer was coded as One while the incorrect answer was Zero. The total score was 7 . The mean ( \pm standard deviation) of the cumulative scores on

Table 3. Association between preventive measures in relation to sex, educational status and health education received. $(\mathbf{n}=82)$

\begin{tabular}{|c|c|c|c|c|c|c|c|}
\hline \multirow{2}{*}{ Characteristics } & \multicolumn{2}{|l|}{ Sex } & \multicolumn{2}{|c|}{ Educational Status } & \multicolumn{2}{|c|}{ Health Education Received } & \multirow{2}{*}{$\begin{array}{l}\text { Total } \\
\text { n(\%) }\end{array}$} \\
\hline & Male & Female & Literate & Illiterate & Yes & No & \\
\hline \multirow[t]{2}{*}{ Use of separate utensil } & $24(63.2 \%)$ & $22(50 \%)$ & $29(54.7 \%)$ & $17(58.6 \%)$ & $30(20.7 \%)$ & $16(59.3 \%)$ & $46(56.1 \%)$ \\
\hline & $20(52.6 \%)$ & $17(60 \%)$ & $20(37.7 \%)$ & $17(58.6 \%)$ & $19(34.5 \%)$ & $18(66.7 \%)$ & $37(45.1 \%)$ \\
\hline Self-isolation & & & & & \multicolumn{2}{|c|}{$\chi^{2}=7.54, p=0.006$} & \\
\hline \multirow[t]{2}{*}{ Use of mask } & $31(81.4 \%)$ & $29(65.9 \%)$ & $40(75.5 \%)$ & $20(68.9 \%)$ & $42(76.4 \%)$ & $18(66.7 \%)$ & $60(73.2 \%)$ \\
\hline & $31(81.6 \%)$ & $33(75 \%)$ & $45(84.9 \%)$ & $19(65.5 \%)$ & $43(78.2 \%)$ & $21(77.8 \%)$ & $64(78.0 \%)$ \\
\hline \multirow{2}{*}{$\begin{array}{l}\text { Covering face while } \\
\text { coughing and sneezing } \\
\text { Using any method of } \\
\text { sputum disposal }\end{array}$} & & & & & \multicolumn{2}{|c|}{$\chi^{2}=4.113, p=0.043$} & \\
\hline & $20(52.6 \%)$ & $17(38.6 \%)$ & $22(41.5 \%)$ & $15(51.7 \%)$ & $22(40 \%)$ & $15(55.5 \%)$ & $37(45.1 \%)$ \\
\hline \multirow{2}{*}{$\begin{array}{l}\text { Keeping your sur- } \\
\text { rounding clean }\end{array}$} & $23(60.5 \%)$ & $28(63.6 \%)$ & $40(75.5 \%)$ & $11(37.9 \%)$ & $40(72.7 \%)$ & $11(3.7 \%)$ & $51(62.2 \%)$ \\
\hline & & & \multicolumn{2}{|c|}{$x^{2}=11.235, p=0.001$} & \multicolumn{2}{|c|}{$\chi^{2}=7.880, p=0.005$} & \\
\hline $\begin{array}{l}\text { Screening of contact } \\
\text { and family members }\end{array}$ & $2(5.3 \%)$ & $6(13.6 \%)$ & $7(13.2 \%)$ & $1(3.4 \%)$ & $6(10.9 \%)$ & $2(7.4 \%)$ & $8(9.8 \%)$ \\
\hline Do not practice & $1(2.6 \%)$ & $2(4.5 \%)$ & $2(3.8 \%)$ & $1(3.4 \%)$ & $3(5.5 \%)$ & $0(0.0 \%)$ & $3(3.7 \%)$ \\
\hline Do not know & $0(0.0 \%)$ & $2(4.5 \%$ & $1(1.9 \%)$ & $1(3.4 \%)$ & $1(1.8 \%)$ & $1(3.7 \%)$ & $2(2.5 \%)$ \\
\hline
\end{tabular}


Bansal et al. Preventive Practices of Tuberculosis Patients in a Municipality of Chitwan..

practice of preventive measures of TB was 3.69 $( \pm 1.65)$. The mean was therefore used as the cut-off for good and poor on practice of preventive behaviour on TB. Thus, $49(59.8 \%)$ of the respondents had good practice on prevention measures of TB while $33(40.2 \%)$ of the respondents had poor practice on preventive measures of TB (Figure 1). Before being diagnosed as a case of TB, $45.1 \%$ of patients disposed sputum

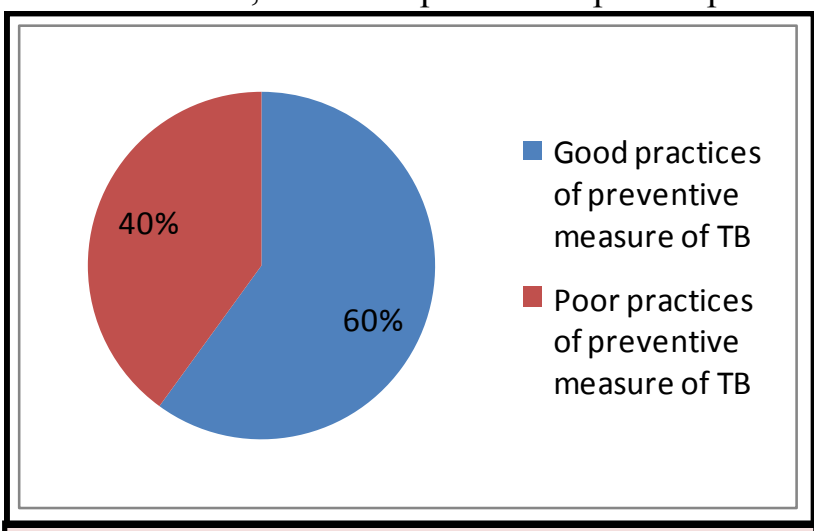

Figure 1. The proportion of respondents with good and poor practice of preventive measures of TB. by indiscriminate spitting and $30.5 \%$ by disposing in dustbin. Also, $15.9 \%$ females used paper/ handkerchief and 7.9\% males used paper/ handkerchief. Also, $13.63 \%$ females disposed in toilets and basins while only $5.26 \%$ males did so (Table 4).

After diagnosis of TB, about $45.1 \%$ patients disposed sputum in dustbin which were more in males $(52.6 \%)$ than females (38.6\%). And $12.2 \%$ patients used paper or handkerchief. Burying of sputum was done by $9.8 \%$ where females were more $(11.4 \%)$ than males $(7.9 \%)$. Similarly, indiscriminate spitting was done by only $6.1 \%$ patients. Safe methods of sputum disposal like burning was practiced by only $3.7 \%$ of patients, pouring boiled water in container was practiced by only $2.4 \%$ of patients. And $1.2 \%$ of patients used 5 $\%$ cresol to destroy sputum. Whereas none of the patients disposed sputum by boiling method (Table 5). Only $6 \%$ of tuberculosis patients practiced safe methods of sputum disposal, remaining $94 \%$ of study patients were found to practice unsafe methods of sputum disposal (Figure 2).

Table 4. Method of sputum disposal before diagnosis of TB. $(n=82)$

\begin{tabular}{|lllllll}
\hline \multirow{2}{*}{ Characteristics } & \multicolumn{2}{c}{ Male } & \multicolumn{2}{c}{ Female } & \multicolumn{2}{c}{ Total } \\
\cline { 2 - 7 } & Frequency & Percentage & Frequency & Percentage & Frequency & Percentage \\
Indiscriminate spitting & 19 & $50 \%$ & 18 & $40.90 \%$ & 37 & $45.10 \%$ \\
Using paper/handkerchief & 3 & $7.90 \%$ & 7 & $15.90 \%$ & 10 & $12.20 \%$ \\
Disposing in dustbin & 13 & $34.20 \%$ & 12 & $27.30 \%$ & 25 & $30.50 \%$ \\
Others (toilet/ basin) & 2 & $5.26 \%$ & 6 & $13.63 \%$ & 8 & $9.75 \%$ \\
\hline \hline
\end{tabular}

Table 5. Method of sputum disposal after diagnosis of TB. $(n=82)$

\begin{tabular}{|c|c|c|c|c|c|c|}
\hline \multirow{2}{*}{ Characteristics } & \multicolumn{2}{|c|}{ Male } & \multicolumn{2}{|c|}{ Female } & \multicolumn{2}{|c|}{ Total } \\
\hline & Frequency & Percentage & Frequency & Percentage & Frequency & Percentage \\
\hline Indiscriminate spitting & 2 & $5.30 \%$ & 3 & $6.80 \%$ & 5 & $6.10 \%$ \\
\hline Using paper/handkerchief & 5 & $13.20 \%$ & 5 & $11.40 \%$ & 10 & $12.20 \%$ \\
\hline Disposing in dustbin & 20 & $52.60 \%$ & 17 & $38.60 \%$ & 37 & $45.10 \%$ \\
\hline Burning & 2 & $5.30 \%$ & 1 & $2.30 \%$ & 3 & $3.70 \%$ \\
\hline Boiling & 0 & $0.00 \%$ & 0 & $0.00 \%$ & 0 & $0.00 \%$ \\
\hline Pouring boiled water in container & 1 & $2.60 \%$ & 1 & $2.30 \%$ & 2 & $2.40 \%$ \\
\hline Burying & 3 & $7.90 \%$ & 5 & $11.40 \%$ & 8 & $9.80 \%$ \\
\hline Use of $5 \%$ cresol & 0 & $0.00 \%$ & 1 & $2.30 \%$ & 1 & $1.20 \%$ \\
\hline Others (toilet/ basin) & 4 & $10.52 \%$ & 7 & $15.90 \%$ & 11 & $13.41 \%$ \\
\hline Not applicable & 6 & $15.78 \%$ & 6 & $13.63 \%$ & 12 & $14.6 \%$ \\
\hline
\end{tabular}


Bansal et al. Preventive Practices of Tuberculosis Patients in a Municipality of Chitwan..

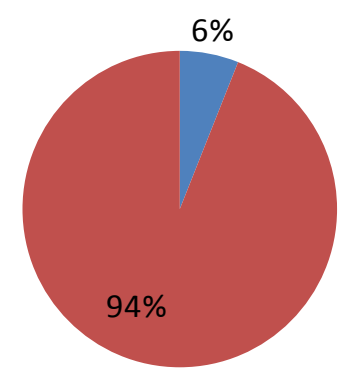

Safe

Unsafe

Figure 2. The proportion of respondents with safe and unsafe disposal of sputum. $(n=82)$
Safe disposal of sputum was done more by males $(60 \%)$ than females $(40 \%)$, more by literate $(60 \%)$ than illiterate $(40 \%)$, more by house workers $(60 \%)$ than other occupations $(40 \%)$, more in patients without family history of TB $4(80 \%)$ than patients who had history of TB in family $1(20 \%)$. Monthly income of more than 10,000 NRs patients were found to dispose sputum safely whereas none of them were found in $<10,000$ NRs income group. Among all patients who received health education only $3(5.45 \%)$ practiced safe sputum disposal whereas remaining $52(94.54 \%)$ practiced unsafe sputum disposal methods (Table 6).

Table 6. Sputum disposal practices. $(\mathrm{n}=82)$

\begin{tabular}{|c|c|c|c|c|}
\hline \multirow{3}{*}{ Category } & \multicolumn{4}{|c|}{ Sputum disposal practices } \\
\hline & \multicolumn{2}{|l|}{ Safe } & \multicolumn{2}{|l|}{ Unsafe } \\
\hline & Frequency & Percentage & Frequency & Percentage \\
\hline \multicolumn{5}{|l|}{ Sex } \\
\hline Male & 3 & 7.9 & 35 & 92.1 \\
\hline Female & 2 & 4.5 & 42 & 95.5 \\
\hline \multicolumn{5}{|l|}{ Education } \\
\hline Literate & 3 & 5.7 & 27 & 93.1 \\
\hline 1lliterate & 2 & 6.9 & 50 & 94.3 \\
\hline \multicolumn{5}{|l|}{ Occupation } \\
\hline Farming & 1 & 1.7 & 12 & 92.3 \\
\hline Service & - & - & 14 & 100 \\
\hline Business & 1 & 11.1 & 8 & 88.9 \\
\hline House worker & 3 & 10.3 & 25 & 89.3 \\
\hline Social service & - & - & 1 & 100 \\
\hline Other & - & - & 7 & 100 \\
\hline \multicolumn{5}{|c|}{ Monthly income of the family (NRs) } \\
\hline$<10,000$ & - & - & 21 & 100 \\
\hline $10,000-20,000$ & 3 & 8.3 & 33 & 91.7 \\
\hline $20,000-30,000$ & 1 & 6.2 & 15 & 93.8 \\
\hline $30,000-40,000$ & - & - & 2 & 100 \\
\hline$>40,000$ & 1 & 14.3 & 6 & 85.7 \\
\hline \multicolumn{5}{|c|}{ History of tuberculosis in the family } \\
\hline Yes & 1 & 5.6 & 17 & 94.4 \\
\hline No & 4 & 6.2 & 60 & 93.8 \\
\hline \multicolumn{5}{|c|}{ Received health education } \\
\hline Yes & 3 & 5.45 & 52 & 94.54 \\
\hline No & 2 & 7.4 & 25 & 92.6 \\
\hline
\end{tabular}




\section{DISCUSSION}

In our study, we found that majority $(45.2 \%)$ of the patients were in $20-40$ years age group, ratio of male to female was $0.8: 1$, maximum patients were literate and most of them were house workers by occupation. In a study by Mei et al., the ratio of male to female patients was $2.36: 1 .{ }^{15}$ We found that $67.10 \%$ of patients had received health education on preventive measures of TB and $32.90 \%$ did not. Similarly, Mei et al., found $67.4 \%$ of patients received health education and $32.6 \%$ did not. ${ }^{15}$

It was observed in our study that majority of patients used mask (73.2\%) and covered their face while coughing and sneezing $(78 \%)$ which was significantly associated with receiving health education $(p=0.043)$. Similarly, a study by Shukla et al., also found $61 \%$ of the patients covered face while coughing/sneezing. ${ }^{16}$ Another study by Yusuf also revealed that $93.8 \%$ of the respondents were covering mouth and nose when coughing or sneezing, whereas $78.1 \%$ kept face mask or paper tissue when they cough or sneeze. ${ }^{17}$ Findings of this study showed that $46 \%$ of patients used separate utensils and $37 \%$ practiced self-isolation to prevent transmission of infection which was significantly associated with receiving health education $(\mathrm{p}=$ 0.006 ). F. M. Yusuf also found $77.6 \%$ respondents controlled private and personal utensils, drinking and eating equipment from droplet infection whereas $20.1 \%$ of the respondents practiced isolation of TB patients. ${ }^{17}$ Also our study found that $62.2 \%$ of patients kept their surrounding clean and was significantly associated with receiving health education $(\mathrm{p}=0.005)$.

In this study $59.8 \%$ of the respondents had good practice on preventive measures of $\mathrm{TB}$ while $40.2 \%$ of the respondents had poor practice on preventive behaviour on TB. Similarly, F. M. Yusuf showed $67.2 \%$ of the respondents had good practice on prevention behaviour on $\mathrm{TB}$ while $32.8 \%$ of the respondents had poor practice on preventive behaviour on TB. ${ }^{17}$

Our study showed before diagnosis of TB $45.1 \%$ of patients disposed sputum by indiscriminate spitting. Lin Mei et al., also found that maximum respondents spit casually before diagnosis of TB. ${ }^{15}$ We found males and females almost equally spitted indiscriminately whereas A. Singh et al., found males spitted indiscriminately more as compared to females. ${ }^{18}$
Our study showed that after diagnosis of TB, indiscriminate spitting was done by only $6.1 \%$ patients. These findings indicate that the number of patients who chose to spit casually decreased significantly before and after diagnosis of TB. About $45.1 \%$ patients disposed sputum in dustbin which were more in males $(52.6 \%)$ than females $(38.6 \%)$ whereas $12.2 \%$ patients used paper or handkerchief. Burying of sputum was done by $9.8 \%$ of patients where females were more $(11.4 \%)$ than males $(7.9 \%)$. Safe methods of sputum disposal like burning was practiced by only $3.7 \%$ of patients, pouring boiled water in container was practiced by only $2.4 \%$ of patients and $1.2 \%$ of patients used $5 \%$ cresol to destroy sputum. None of the patients disposed sputum by boiling method. Similarly, Lin Mei et al., found sputum disposal method in the first month of treatment, 130 spit casually, 124 used a sputum cup, 37 chose to bury their sputum, 126 used a handkerchief to collect their sputum, 100 spit in a designated location, and 245 said they used other methods to dispose of their sputum or that they had no sputum. ${ }^{15}$

We found that only $6 \%$ of tuberculosis patients practiced safe methods of sputum disposal whereas A. Singh et al., found safe sputum disposal was practised by $46.4 \%$ of the study subjects. ${ }^{18}$ Another study by D. C. Cheriamane et al., found $18 \%$ of patients followed correct sputum disposal method. ${ }^{10}$ Another study by T. Rekha et al., found safe sputum disposal was practised by $49.5 \%$ of the study subjects. ${ }^{19}$ Our study shows that safe disposal of sputum was done more by males $(60 \%)$ than females $(40 \%)$, more by literate $60 \%$ than illiterate $(40 \%)$, more by house workers $(60 \%)$ than other occupations $(40 \%)$, more in patients without family history of TB $(80 \%)$ than patients who had history of TB in family $(20 \%)$. Whereas, T. Rekha et al., found more females than males disposed of sputum safely $(61.8 \%$ vs. $38.2 \%)$, as did more subjects of low than middle socio-economic status $(75 \%$ vs. $25 \%)$.

More subjects without a family history of TB $(70 \%$ vs. $45 \%$,), and more literate than illiterate subjects (59\% vs. $35.7 \%)$ practiced safe sputum disposal methods. ${ }^{19}$ A. Singh et al., also found more females $70.4 \%$ than males $39.2 \%$ disposed sputum safely, as did more subjects of middle than low socioeconomic status ( $74.1 \%$ vs. $22.2 \%)$. A $70.9 \%$ of the subjects with a family history of TB practiced safe sputum disposal methods as compared to $39.5 \%$ subjects without a family history of TB practiced the same. Similarly, more literate than illiterate 
subjects $(57.5 \%$ vs. $28.6 \%)$ practiced safe sputum disposal methods. ${ }^{18}$ Lin Mei et al., found that $64.2 \%$ of men and $79.0 \%$ of women disposed of sputum correctly and by level of education who were more educated were more likely to dispose of sputum correctly. ${ }^{15}$

In our study among all patients who received health education only $5.45 \%$ practiced safe sputum disposal whereas remaining $94.54 \%$ practiced unsafe sputum disposal methods. Whereas Lin Mei et al found that among who received health education, $70.7 \%$ practiced correct method of disposal of sputum. ${ }^{15}$

This study was conducted only in DOTS centres of Bharatpur municipality, so these findings cannot be truly representative of entire population.

\section{REFERENCES}

1. World Health Organization: Tuberculosis (TB). http://www.who.int/mediacentre/ factsheets/fs104/en/ (2018). Accessed 19 Feb 2018.

2. Disease Control: Tuberculosis. In: Annual Report Department of Health Services 2072/73 (2015/2016). Kathmandu: Government of Nepal, Ministry of Health, Department of Health Services, Kathmandu, Nepal; 2017. p.138. https://dohs.gov.np/wp-content/

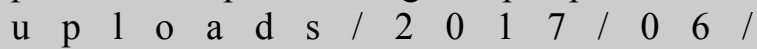
DoHS_Annual_Report_2072_73.pdf

3. TB Prevention Services. In: National Tuberculosis Program Nepal, Annual Report 2072/73 (2016). Government of Nepal, Ministry of Health and Population, Department of Health Services, National Tuberculosis Center, Thimi, Bhaktapur, 2017. p.40. https:// nepalntp.gov.np/wp-content/uploads/2018/11/ T B_A n nual-Report - N T P N - 2016 compressed.pdf

4. Guidelines on Airborne Infection Control in Healthcare and Other Settings. New Delhi: Directorate General of Health Services, Ministry of Health \& Family Welfare, Nirman Bhawan, New Delhi; April 2010. p. 56,68 . h t t p : / / u p s a c s.i n / pdfGuidelines_on_Airborne_Infection_Control April2010Provisional.pdf

5. Marx FM, Dunbar R, Enarson DA, Beyers N. The rate of sputum smear-positive tuberculosis after treatment default in a high-burden setting: A retrospective cohort study. PLoS One. 2012; d o i : 7 ( 9 ) : e 45724 . ht tp s :// www.ncbi.nlm.nih.gov/pubmed/23049846

6. Nagaraja SB, Kumar AM, Sachdeva KS,

\section{CONCLUSIONS}

Therefore, to prevent transmission of $\mathrm{TB}$ in the community the patients and family members should be well educated on practicing different preventive measures. The preventive measures strategy in the transmission of tuberculosis needs to be further strengthened. Monitoring of preventive practices of these patients through DOTS should be given priority along with other integrated treatment and management strategy if we envisioned to end TB by 2035.

\section{ACKNOWLEDGEMENTS}

We thank all the staffs of the DOTS centres for their co-operation.

\section{Conflict of Interest: None.}

Ramachandran R, Satyanarayana S, Bansal A, et al. Is one sputum specimen as good as two during follow-up cultures for monitoring multi drug resistant tuberculosis patients in India? PLoS One. 2012; doi:7(9):e45554. https:// journals.plos.org/plosone/article?id=10.1371/ journal.pone. 0045554

7. Rathored J, Sharma SK, Singh B, Banavaliker JN, Sreenivas V, Srivastava AK, et al. Risk and outcome of multidrug-resistant tuberculosis: Vitamin D receptor polymorphisms and serum 25(OH)D. Int J Tuberc Lung Dis. 2012;16:1522 -1528. https://doi.org/10.5588/ijtld.12.0122.

8. Tamhane A, Ambe G, Vermund SH, Kohler CL, Karande A, Sathiakumar N. Pulmonary tuberculosis in mumbai, India: Factors responsible for patient and treatment delays. Int J Prev Med. 2012;3:569-580. https:// www.ncbi.nlm.nih.gov/pmc/articles/ PMC3429805/

9. Breedlove R, Bruck L, Comerford K, eds. Straight A's in pathophysiology. Philadelphia, PA, USA: Lippincott Williams and Wilkins; 2005. p. 608. https://www.alibris.com/StraightAs-in-Pathophysiology/book/28464171

10.Cheriamane D, Mohammed G, Verma B, Kandal I, Hari DT, Nian SE, et al. Knowledge of Cough Hygiene And Disposal of Sputum in Patients with Pulmonary Tuberculosis. IOSR Journal of Dental and Medical Sciences. 2017;16(02):82-85; doi: 10.9790/0853$\begin{array}{llllllllllll}16 & 0 & 2 & 0 & 2 & 8 & 2 & 8 & 5\end{array}$. h t t p s : / / pdfs.semanticscholar.org/3bcd/91 eff2135f6fde0 cf5759198ab3f027a15f7.pdf

11.World Health Organization. Blood safety and clinical technology: guideline on standard operating procedures for microbiology: 
Bansal et al. Preventive Practices of Tuberculosis Patients in a Municipality of Chitwan..

Tuberculosis. http://209.61.208.233/en/ Section $10 /$ Section $17 /$ Section53/ Section 482 (2007). Accessed February 2013.

12.Bhattacharyya K, Rama R, Mitra SP, Bhattacharyya SK, Sarkar TK, Dasgupta U, et al. Perceptions and practices of sputum-positive pulmonary tuberculosis patients regarding their disease and its management. NTI Bulletin. 2005;41:11-17. http://medind.nic.in/nac/t05/i1/ nact05ilp11.pdf

13.Disease Control: Tuberculosis. In: Annual Report Department of Health Services 2071/72 (2014/2015). Kathmandu: Government of Nepal, Ministry of Health, Department of Health Services, Kathmandu, Nepal. 2016. p.146. http://dohs.gov.np/wp-content/

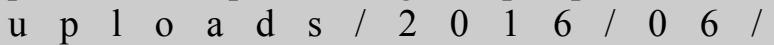
Annual_Report_FY_2071_72.pdf

14.Park $\bar{K}$. Principles of epidemiology and epidemiological methods. In: Park's textbook of preventive and social medicine. 23rd ed. Jabalpur: Bhanot; 2015. p.130-31.

15.Mei L, Tobe RG, Geng H, Ma YB, Li RY, Wang WB, et al. A cross-sectional study of sputum handling by and supervision of patients with pulmonary tuberculosis treated at home in China. Biosci Trends. 2012 Dec;6(6):296-302; doi: 10.5582/bst.2012.v6.6.296. http:// www.biosciencetrends.com/action/ downloaddoc.php?docid $=608$
16.Shukla A, Chauhan R, Dalal P. Study of Knowledge and Practice of Sputum Disposal among TB Patients of Ahmedabad City. NHL Journal of Medical Sciences. 2013;2(2):22-25. https://scholar.google.com/scholar? as_q=Study + of + Knowledge + and + Practice + of + Sputum + Disposal + among + TB + Patients + of + Ah medabad+City

17.Yusuf FM. Assessment of Prevention Behavioural Practices Among Adult Tuberculosis Patients in Eastleigh Division, Nairobi County, Kenya. 2014. https:// www.scribd.com/document/274955136/ Assessment-of-Prevention-BehaviouralPractices-Among-Adult-Tuberculosis-Patientsin-Eastleigh-Division-Nairobi-County-Kenya. Accessed 21 Aug 2018.

18.Singh A, Goyal V, Goel S. Sputum Collection and Disposal Perceptions and Practices Among Pulmonary Tuberculosis Patients from Northern India. Journal of Clinical and Diagnostic Research. Journal of Clinical and Diagnostic Research. 2016;10(12):16-18. https:// dx.doi.org/10.7860\%2FJCDR\%2F2016\% 2F21673.8978

19.Rekha T, Singh P, Unnikrishnan B, Mithra PP, Kumar N, Prasad KDV, et al. Sputum collection and disposal among pulmonary tuberculosis patients in coastal South India. The International Journal of Tuberculosis and Lung

Citation: Bansal P, Khatiwada D, Upadhyay HP. Preventive Practices of Tuberculosis Patients in a Municipality of Chitwan District, Nepal. JCMS Nepal. 2019;15(1):59-66. 